\title{
Riding tandem: an organic and collaborative approach to research in vocational education and training
}

\author{
Cathy Ellis ${ }^{\mathrm{a} *}$, Alec Dyer ${ }^{\mathrm{b}}$ and Dominic Thompson ${ }^{\mathrm{b}}$ \\ ${ }^{a}$ School of Education Communication and Language Sciences, University of Newcastle, \\ Newcastle upon Tyne, UK; ${ }^{b}$ Business Department, Highbury College, Portsmouth, UK
}

(Received 17 July 2014; final version received 18 July 2014)

\begin{abstract}
This study set out to explore the use of the Internet in peer-to-peer learning environments within vocational education and training and to investigate whether this approach could replace traditional teaching and learning. A mixed methods design, including classroom observations, design experiments, interviews and questionnaires was adopted. Although this study represents a mid-term report on work in progress only, a number of observations can nevertheless be made about the process of conducting research within Further Education (FE) colleges. Whilst, traditionally, the pursuit of research is not a priority within FE colleges, this study has encouraged lecturers in Highbury College, Portsmouth, United Kingdom to trial a research-based approach to curriculum development. They have worked as co-researchers in the study from the conceptual phase to implementation. This paper outlines the process of conducting research in partnership with Business lecturers at Highbury College. It presents preliminary findings based on the researcher and lecturers' reflections on the research methodology and process followed over a period of 9 months.
\end{abstract}

Keywords: Emergent learning; FE Colleges; SOLE; vocational education and training

\section{Introduction}

Further Education Colleges form the backbone of the Vocational Education and Training (VET) system in the United Kingdom. It is a sector 'where the tectonic plates of the education system and the labour market meet' (Keep 2012), and, in its simplest terms, the purpose of the VET system is to prepare young people explicitly for work. Given that this is a sector intended to mirror prevailing and emerging industrial needs, it is regularly criticised for lagging behind the workplace in its adoption of digital technologies (Office for Standards in Education, Children's Services and Skills 2009; Ufi Charitable Trust 2012). Whilst the workplace and the wider economy has seen seismic shifts in business models and working practices as a result of digital technologies (Brynjolfsson and McAfee 2014; Frey and Osborne 2013), the vocational curriculum in FE Colleges has merely dabbled at the margins. The status quo in pedagogical practice remains that of a compromise position where technology is used to shore up out-dated practices rather than to innovate practice (Becta 2010; Blin and Munro 2008).

*Corresponding author. Email: Catherine.ellis@newcastle.ac.uk 
This compromise is, perhaps, the result of the underlying tension between the concepts of 'disruption' and 'control' which lie at the heart of the discourse on digital technologies in the education world. Rather than delivering the learning experiences now commonly accepted as a fundamental requirement for personal, social and economic prosperity in the 21st century (Castells 2009; Trilling and Fadel 2012; Zhao 2012), the default practice remains that of replicating or supplementing traditional activities.

As far as FE colleges are concerned, however, there are signs that this may be about to change. Firstly, recent statements from the UK Government Department responsible for VET policy have turned the spotlight on technology, stating:

New technology will play an indispensable role in transforming vocational training. Technology is both directly improving the user experience and raising standards, as users make better choices with easy access to information. Our colleges and providers must take advantage of such opportunities. (BIS and DFE 2013, p. 7)

Secondly, the recently published report from the UK Further Education Learning and Technology Advisory Group (FELTAG) proposed a number of radical measures, including a recommendation to make mandatory 'the inclusion in every publiclyfunded learning programme from $2015 / 16$ of a $10 \%$ wholly online component, with incentives to increase this to $50 \%$ by $2017 / 18$ ' (BIS 2014, p. 23). Whether $50 \%$ is a desirable option for students in FE colleges, or, indeed, what $50 \%$ online would actually mean in practice, remains to be seen, but the tone of the rhetoric used by policy makers is clearly shifting to one in which the dominant lecturer-centric model of pedagogy is being challenged. It is within this context that this research project has taken shape.

The research project set out to explore whether the methodology of Self-Organised Learning Environments (SOLEs) as developed by Sugata Mitra in the school sector (Dolan et al. 2013), could be applied successfully within VET courses. Study experiments have taken place to date with 150 students across three VET colleges - two in the UK and one in India - in the subject areas of Automotive Studies, Beauty Therapy, Business, Construction, and Hairdressing. The two UK colleges were identified on the basis of having different demographic and curriculum profiles whilst operating in the same VET system, and the inclusion of an Indian College would enable comparisons to be made with other VET systems. The choice of India was further influenced by the recent focus given to the Indian VET system by the UK Government Department for Business Innovation and Skills (BIS), and the formation of Association of Colleges (AoC) India, launched by the UK Minister for Skills and Enterprise, on a delegation to India in 2013 (Linford 2013).

The focus of this paper is on the experience of conducting experiments in the Business subject area at Highbury College where curriculum experimentation is now taking place on a regular basis. Highbury College is a general Further Education College located in Portsmouth, United Kingdom. It trains over 10,000 students each year in a range of vocational subjects and levels. Over a number of years, the college has established a learning culture which supports curriculum enquiry, and an evidence-based improvement strategy is articulated in its pedagogical framework (Highbury College 2013). This paper reports on research in progress and draws some initial observations about the process of conducting research within live teaching environments, highlighting some initial reflections about the effectiveness of SOLE, 
and illustrating how this project is establishing a culture of pedagogical enquiry in Highbury College.

\section{Background}

\section{Context for the study}

Within the FE system in the UK, the role of employers in shaping policy has been prioritised by successive governments with the aim of establishing a more demand-led and employer-led system (Keep 2006). However, a number of recent studies from employer bodies have concluded that many students leave FE poorly equipped for the workplace (CBI 2012; UKCES 2014) and question whether the traditional model of VET is meeting the needs of today's students any longer. UKCES, for example, paints a picture of convergence and cross-disciplinary working becoming key features for work in the future, and explores how these skills might best be developed in the FE sector.

A consensus is emerging that the traditional industrial model of VET no longer serves the pedagogical needs of today's students (Zhao 2012) and the future of FE colleges, as they are currently constituted, is being challenged. With a world of expert opinion and comment available on the Internet at the click of a mouse, the question arises as to what knowledge and skills now actually need to be taught in formal settings. It would seem that colleges, if they are to remain relevant to students, employers and the wider economy, need to rethink the curriculum in terms of content and pedagogy so that it better reflects the demands of an increasingly digital and networked society (Castells 2009). What is needed, perhaps, is what Castells describes as 'self-programmable' workers, constantly retraining and relearning throughout working life, with the Internet firmly established as 'the durable companion of adult life' (Castells 2009, p. 91). The workplace increasingly demands inter-disciplinary and multi-disciplinary competencies and, to reflect this, recruitment is becoming geared much more to college leavers' aptitudes for work rather than to qualifications obtained (CBI/Pearson 2014).

The pace and impact of technological change in the workplace, therefore, means that the VET curriculum is often out-dated by the time students actually start their courses and previously taught skills are rendered obsolete from the outset (Frey and Osborne 2013). So, against such a backdrop of ferocious automation and rapid obsolescence of equipment and skills in the workplace, as technology advances at an increasingly phenomenal rate, how best should colleges prepare students to meet these challenges? To answer this question, a brief overview of current thinking on VET pedagogy within a digital environment would help to set the framework for this project for which the preliminary findings obtained are the subject matter of this paper.

\section{Student-centred learning within a digital environment}

According to Lucas et al. (2012), there is a default pedagogy adopted by VET lecturers which lies in the spectrum of 'learning by doing' or 'experiential learning'. Such student-centred and experiential models of learning can be seen as part of a pedagogic tradition dating back to the traditional apprenticeship model of VET which was largely based on learning by watching, working alongside peers and 
demonstrating competence through projects such as the production of an 'apprentice piece'. It exemplifies what Lave and Wenger (1991) refer to as 'communities of practice' and promotes the notion of 'situated learning' which is context-driven and based on the experience of learning as a social phenomenon. Following from this, projectbased learning came to the fore as a pedagogical methodology, providing simulated practice of workplace skills. Here it was hoped that students would become equipped with the skills needed for the informal learning increasingly practised in the workplace. Finally, self-directed or self-paced learning, which supports the learner progressing at their own pace and taking control of their learning, has emerged as a pedagogical approach in recent years, largely influenced by the availability of computer-based learning resources. A common strand underpins all these forms of learning: it is the emphasis on the individual learner managing their own learning whilst supported by the lecturer who adopts the role of facilitator (Rogers 1983).

Alongside this practice colleges are attempting to harness digital technologies to support learning (BIS 2014). The introduction of learning platforms, the adoption of social networking tools such as Facebook and Twitter and, more recently, the development of Massive Open Online Courses (MOOCs), point to the pivotal role that digital technologies are assuming in the 21st century VET paradigm. Given this background, and given the twin realities of the requirement for digitally competent workers for an increasingly digital workplace on the one hand, and the adoption of digital technologies by young adults on the other, the framework for a 21st century VET pedagogy cannot ignore the central role of digital technologies for teaching, learning and assessment. In short, if the workplace is to be increasingly defined by its digital architecture, then the period of learning which precedes employment needs to reflect this or risk being seen as anachronistic in its practice.

In the light of the above, this study set out to explore whether the method of SelfOrganised Learning Environments (SOLEs), which is being adopted in school settings around the world (Davis 2013), could usefully form part of the pedagogical spectrum for the 21 st century VET institution. The approach of SOLEs, as developed by Mitra (2013), rests on the principles of peer-to-peer learning in Internet-rich environments. Mitra's experiments established that deep learning can take place when learning is structured around the principles of self-organising systems, that groups of children can teach themselves, and that the absence of the lecturer can be a powerful pedagogical tool (Mitra, Dangwal, and Thadani 2008). This approach sits within a long tradition in FE Colleges of student-centred and discovery learning but redefines such approaches for the digital age with its emphasis on access to the Internet by students working in randomly chosen groups on a range of open questions. Interaction with the task is unstructured and the students are not directed towards resources by the lecturer. The aim of SOLE is to hand to students the total freedom to explore the question from whatever viewpoint occurs to them and see where such exploration takes them. Indeed, in the context of VET, the Internet could perhaps be described as the digital equivalent of the apprentice master- offering virtual and on demand access to expert demonstrations and explanations. Working together in groups, students collaborate in a process of collective learning - reflecting the process of 'emergent learning' which occurs in real workplace settings. Such learning is very similar to the realities of learning on the job when employees are required to troubleshoot emerging problems and acquire new skills independently or with colleagues. Given these similarities, the SOLE model could be seen as an appropriate 
methodology to develop the confident, proactive and self-programmable workers needed for today's global workplace.

\section{Developing the principles of pedagogical enquiry in further education}

The significance of research activity as a means to both personal and professional development is well documented (Barker 2005; BERA and RSA 2014; Vogrinc and Zuljan 2009). Its role as an important reflective activity for practitioners was stressed by Stenhouse (1975), whilst work in the late 1990s (Hargreaves 1996) emphasised the concept of lecturers as producers and users of research. Most of this research, however, is concerned with teachers in the school system. The FE system has tended to fall outside of mainstream research activity, with FE lecturers often experiencing institutional barriers in undertaking research (Scaife 2004). In addition, there is a question of confidence to be addressed in the FE sector in the conducting of research, given what Hillier and Morris (2010) refer to as

The real sense that researchers located in higher education (and government) did not recognise the value of, or indeed the existence of, research conducted by colleagues in FE'. (p. 92)

The absence of a core of FE research capacity in colleges was further compounded by the fact that there was no formal requirement for a lecturer qualification in the FE sector until 2001, when workforce reforms were set in train to require a teaching qualification for those entering the sector, and making mandatory continuing professional development (Foster 2005). The concepts of 'licence to practice' and the 'reflective practitioner' were both subsequently championed by the Institute for Learning, the professional body for lecturers working in further education. Latterly, however, this policy has become fragmented and, in 2013, the requirement for FE lecturers and trainers to gain a teaching qualification was removed. Furthermore, much of the research activity that occurs in FE colleges takes the form of colleges being invited to be mere participants, as opposed to actual partners, with activity being linked to incentives for funding to support lecturer release and engagement with research. Whilst the concept of 'research practitioner' is not a new phenomenon in FE (Hillier and Morris 2010), it is worth noting that, as far as this study is concerned, commitment to the research activity was secured without any external pressures or funding incentives. The lecturers involved have been fully 'partners' in the research, as opposed to 'participants', and have contributed at every stage of the process. This level of engagement does, we believe, provide a model for other colleges to consider as they seek to identify new modes of delivery as recommended in the recent FELTAG report (BIS 2014).

\section{Research methodology}

\section{Research design-pragmatism in the classroom}

The methodology adopted for this study has been that of design experiments within an overarching case study framework. In practice, this has meant working in partnership with the college and developing the research design with the lecturers involved, based on a dual objective: to study learning in context; and to develop effective classroom interventions (Gorard, Roberts, and Taylor 2004). The potential 


\section{Ellis et al.}

limitations of case studies to produce generalised outcomes (Stark and Torrance 2005; Yin 2014) has been mitigated in this study by the adoption of multiple sources of evidence to enable a triangulation of findings. Classroom experiments were therefore complemented by other datasets - video footage, interviews and questionnaires. This approach embraces the methodological diversity and pluralism of mixed methods, as advocated by Johnson and Onwuegbuzie (2004), and is generally considered to be the most appropriate methodology for a study such as this, given its widespread adoption in the still nascent field of educational technology research (Jones and Kennedy 2012).

The research design consisted of running a series of controlled classroom experiments based on the techniques of random assignment administered using controlled groups of students who all completed standardised assessments so that a comparative analysis could be made. The steps outlined below were applied to all subject areas and taken together comprised the experiment cycle. At the end of each cycle data was collected in the form of test scores and audio and video interviews; the groups were then rotated and the cycle repeated so that each group experienced both the traditional and SOLE approach in a related topic area (Figure 1).

From the start of the process, the researcher has been integrated into the teaching team and adopted the role of 'practitioner researcher'; this was mirrored by the lecturers stepping naturally into the role of 'research practitioners' (Cochran-Smith and Lytle 2009). Following a process of established protocols for ethical clearance, students met the researcher at the start of the term and were given written and verbal

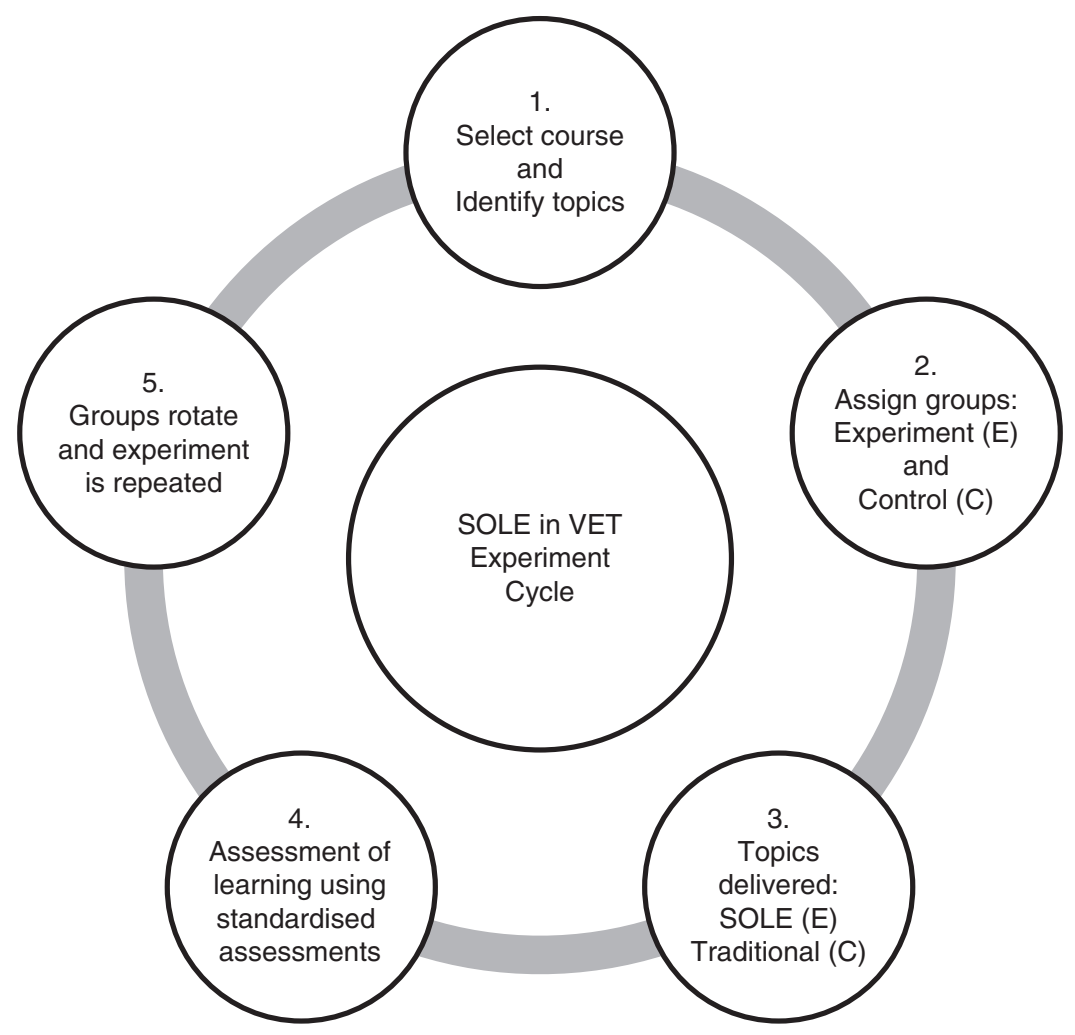

Figure 1. SOLE experiment cycle. 
briefings to the study before it commenced. The process has been to integrate the intervention into the natural setting of the classroom and make the experience as least disruptive as possible for the students and lecturers. The experience of early classroom trials and discussions concerning suitable research methods ruled out the application of pre-intervention measurements as in all cases students had no prior experience of the skills being taught and, therefore, testing prior competency in the skills area was not appropriate. The most extreme examples of this occurred in a construction experiment which involved the erection of a mobile scaffold and a hairdressing experiment which involved demonstrating competencies in cutting hair. In both these cases the use of pure experimental design was not appropriate and therefore alternatives to present a triangulation of findings (combining qualitative classroom observations and video interviews with test data and questionnaires) led to the decision to introduce design-based thinking into the overarching methodology (Gorard, Roberts, and Taylor 2004; Reeves, Herrington, and Oliver 2005). The features of this study which were particularly pertinent in this decision were

- the situating of the research within the daily practice of teaching and learning and with active collaboration of lecturers and students in the process,

- existing and theoretical principles (SOLE and its antecedents of studentcentred learning) and technological innovations informed the research; and

- iterative cycles of testing and refinement of SOLE in context were employed.

\section{Traditional teaching and SOLE: some observations Researcher reflections}

This paper has attempted to describe the process in which new pedagogical approaches have emerged in vocational education and training to meet the changing needs of the modern workplace. It is too early in the research to present a detailed analysis of the results obtained from the experiments, but the following observations and reflections from the researcher and lecturer perspectives might prove instructive. Students are often surprised at how much they can learn from the Internet - we tend to assume that they are totally 'net savvy' but often their use is, in fact, limited to social media activity. Younger students select video content once they realise it is acceptable to make a noise in the classroom. Older students, on the whole, search for text-based content. The experiments have prompted discussions with students about how they prefer to learn. Some of the comments made at the end of the lessons are listed below:

I thought it was good. We learnt from each other and she (referring to other student taking part in the interview) could pick out something I'd not noticed. So, like for then, it all adds up in your head as you go along. (Business student)

We enjoyed the freedom of working with friends. With friends it helps to work more efficiently. (Automotive student)

With the Internet, and your team, you make a very good team. (Beauty student)

In all of the assessments which have taken place to date, students who had been in the SOLE lesson mostly scored as well, and sometimes better, than students who had 
been taught by the lecturer in the lesson. Although still at an early stage of data analysis, this is an interesting finding, given that the students in the SOLE lesson did not have access to the lecturer's expertise to direct them and keep them on track in the lessons. Finally, lecturers have continued to experiment with the method themselves beyond the initial experiment cycle. Lessons have been videoed and lecturers are reflecting on the learning dynamics which takes place in SOLE lessons and a culture of supported experimentation is becoming established within the college.

\section{Lecturer reflections}

Before being approached to be part of this study, the use of tools such as Skype, Google Hangouts, and YouTube, etc. was commonplace within curriculum design. However, its use was never formalised or studied as part of an experiment focussing on teaching and learning. In addition, project-based learning and group work are activities that students engage with on a daily basis but always with a strong steering from lecturers in terms of the requirements and desirable outcomes.

Initially, Self-Organised Learning Environments (SOLEs) seemed a somewhat confusing approach to something well established in our practice (namely, experiential learning and 'learning by doing') but, after further discussion and analysis, it was clear that this approach was something different; it was building on these foundations, taking learning as an emergent phenomenon, and combining theories of learning (Carl Rogers' student centred learning, for example) with the possibilities that the Internet has created for learning.

At first, there was a degree of scepticism. This was mainly due to the pressures put upon all educators in the form of progression rates, success rates, value-added scores and UCAS points. However, the design of the study was such that there would be no detrimental effect on the students' studies if the SOLE approach did not engage them and allow them to succeed - which was an important factor in deciding whether to take part in the study or not. Working on the research design from the early stages meant that the final design was something of a collaboration, which was particularly gratifying. It was also important to be given the opportunity to review the design as early iterations of the experiments influenced our future decisions about topic choices and timings of the experiments.

Seeing the first SOLE session, delivered to a level 3 BTEC National Diploma in Business, was a rather strange experience to begin with. Students were introduced, very succinctly, to the idea, given the question, asked to form groups of four to work around one computer, then literally 'let loose' to complete their research. The initial perception was that it wouldn't work, that students would struggle with all working on one computer and that one or two students would do all the work. The students were a little slow at first to understand the requirements of the task but they soon began working as a team to research, discuss and answer the question posed. At the end of the session each group then fed back the key points of the research completed. Most surprising was the fact that, after analysing the information presented by the students and comparing it with the material in the traditionally taught session, the students in the SOLE session had covered the majority of the traditional material that would have been delivered and also discovered a considerable amount of extra content that would not necessarily have been discussed as part of the traditional session. This in itself was an interesting outcome and something which we would see repeated in subsequent SOLE lessons. 
Initially, it was thought that adopting the SOLE approach would mean topics and sessions would have to be constantly re-taught due to the prescriptive nature of the criteria that need to be covered to pass a BTEC National Diploma. There have been occasions where specific topics have had to be taught traditionally, after a SOLE session, and there have been times when areas have been re-visited where students did not understand the concept in the way that was laid down by the awarding body. However, in terms of creating deeper, rather than surface, learning, it can be argued that, although the specific theory required for the diploma was not addressed, understanding of the topic was in fact greater.

Delivering SOLE sessions can actually be a strange, frustrating experience. Lecturers are programmed to help students find the answer and have an objective for the specific knowledge that is necessary for the students to pass a test or write an assignment, and their goal is to facilitate the student to get to that desired end. However, in the SOLE sessions the lecturer simply poses the question and then facilitates the review stage of the session. It is extremely hard when asked questions such as, 'What do I need to do?' or, 'Is this right?' not to answer the question and/or guide the student in the correct direction. The notion of SOLE sessions being 'selfcorrecting, where groups naturally come to the right conclusion seemed, again, a little hard to conceive until examples of this happening occurred in several sessions.

After the initial few stages and experiments, SOLE sessions quickly became integrated into the Business team's schemes of work; students became more confident during the sessions and lecturers became more creative in their approaches. In addition, we noted that, contrary to original apprehensions and fears of time being lost, the method has actually resulted in time gains, providing lecturers with greater freedom to experiment and offer alternative lessons and enrichment activities where students can learn without the restriction of pre-defined assessment criteria.

\section{Discussion}

From the fieldwork undertaken to date, questions have been raised about the spectrum of pedagogical approaches which can be adopted in the VET curriculum. These questions have prompted discussions by teachers on how they should approach teaching, learning and assessment. Students have also engaged in the debate and reflected on what makes learning effective for them. Lecturers have considered how they can more effectively develop in students the capabilities to research, analyse, synthesise, and evaluate information and sources related to their vocational area, and what this might mean for their role as vocational experts.

The observations in this paper are offered at the midway stage of a research project and are therefore presented as indicative and preliminary. Nevertheless, what does seem to be emerging from this study is a number of potential benefits to applying SOLEs in the VET curriculum. First, the traditional apprenticeship model was largely based on learning by observing, working alongside peers and demonstrating competence through the production of an 'apprentice piece'. The practice of SOLE could be seen to be redesigning the apprenticeship model of learning within a digital paradigm.

Second, students are developing knowledge and understanding of the topic without expert lecturer input and are being motivated in this process by the freedom to learn which SOLE offers. A number of times students were observed expressing surprise at the range of materials available for their subject. We run the risk of 
assuming the today's net 'savvy' generation already know this as much of the time they use the Internet in social rather than learning contexts. Third, students do seem to develop confidence and are more adept at teamwork and leadership over the course of SOLE lessons. Fourth, in most cases the assessment scores are broadly level between the control and experiment groups, which is itself an interesting result given the students in the SOLE lesson do not have access to a lecturer to guide them to relevant information and keep them on task. In all of the lessons described in this paper, the teachers remarked on the way the SOLE method appeared to energise the students. Finally, one of the most constant features in the post-SOLE lessons feedback was the in depth discussions which took place with students about the process of learning. Students reflected on what worked for them, and even considered whether the topics chosen by the lecturer were appropriate or not for the SOLE approach. There were examples of students requesting the SOLE approach in subsequent lessons as they recognised its relevance to the topic under investigation. This aspect of SOLE in highlighting modes of preferred learning amongst VET students may turn out to be one of the more enduring benefits of employing SOLE in Vocational Education and Training and it will be examined further during the remainder of this research.

Lecturers are reflecting on their role and how face-to-face presence adds value beyond the transmission of information which is now widely available on the Internet. Students have begun to question exactly how they learn best. They have begun to consider how much input they need from the lecturer, and how much information they can actually find out on their own and from their peers depending on their own perceived ability or confidence in a particular subject area.

As a result of this study, Business students at Highbury College have become more responsible for their learning, and have exhibited greater motivation to complete tasks outside of their normal classroom setting, providing lecturers with much welcomed flexibility. Additionally, colleagues have expressed an interest in exploring the method and a cascade process has started with lecturers across the college.

\section{Conclusion}

This study set out from the conceptual phase to be embedded within an FE college and for the interventions to take place in live classroom settings in a partnership between researcher and lecturer. Details of the initial research design were presented to the lecturers and, following this consultation and a review of initial trials, the research design was agreed. Not only has this project considered a specific pedagogical question within the context of learning technology in VET, it has also provided a platform for the lecturers involved to be both producers and users of the research. It was always the intention to utilise a partnership model in working with the colleges, but the level of enthusiasm and engagement far exceeded expectations, and stimulated the journey of collaborative enquiry described above. The experience of this research project has highlighted the benefits of pedagogical enquiry as a core component of teaching practice and professional development in FE colleges. It has energised the lecturers and the students who have participated in the project and it is continuing to stimulate ideas about teaching, learning and assessment. 


\section{References}

Barker, P. (2005) Research in Schools and Colleges, National Educational Research Forum, Working Paper 7.2, Bristol.

Becta. (2010) Next Generation Learning Plan: The Implementation Plan for Further Education and Skills. BECTA, Coventry.

BERA and RSA. (2014) The Role of Research in Lecturer Education: Reviewing the Evidence, [online] Available at: http://www.thersa.org/action-research-centre/learning,-cognitionand-creativity/education/lecturers-and-lecturer-education/the-role-of-research-in-lecturereducation-reviewing-the-evidence

BIS. (2014) Further Education Learning Technology Advisory Group: Paths Forward to a Digital Future for Further Education and Skills, [online] Available at: http://feltag.org.uk/ recommendations/

BIS and DFE. (2013) Rigour and Responsiveness in Skills, [online] Available at: https://www. gov.uk/government/publications/rigour-and-responsiveness-in-skills

Blin, F. \& Munro, M. (2008) 'Why hasn't technology disrupted academics' teaching practices? Understanding resistance to change through the lens of activity theory', Computers \& Education, vol. 50, no. 2, pp. 475-490.

Brynjolfsson, E. \& McAfee, A. (2014) The Second Machine Age: Work, Progress, and Prosperity in a Time of Brilliant Technologies, W.W. Norton \& Company, New York.

Castells, M. (2009) The Internet Galaxy: Reflections on the Internet, Business, and Society, Oxford University Press, New York.

CBI. (2012) First Steps. Confederation of Business Industry, London.

CBI/Pearson. (2014) Education and Skills Survey 2014, [online] Available at: http://www.cbi. org.uk/infographics/education-survey-2014/

Cochran-Smith, M. \& Lytle, S. L. (2009) Inquiry as Stance: Practitioner Research for the Next Generation, Teachers College Press, New York.

Davis, J. (2013) How a Radical New Teaching Method Could Unleash a Generation of Geniuses, Wired Business, [online] Available at: http://www.wired.com/2013/10/free-thinkers

Dolan, P., et al., (2013) 'Self-organised learning environments (SOLEs) in an English school: an example of transformative pedagogy?', The Online Educational Research, [online] Available at: http://www.oerj.org/View?action=viewPDF\&paper=109

Foster, A. (2005) Realising the Potential: A Review of the Role of Further Education Colleges, DfES, Nottingham.

Frey, C. B. \& Osborne, M. A. (2013) 'The Future of Employment: How Susceptible are Jobs to Computerisation?', Oxford Martin School - The University of Oxford, [online] Available at: http://www.oxfordmartin.ox.ac.uk/publications/view/1314

Gorard, S., Roberts, K. \& Taylor, C. (2004) 'What kind of creature is a design experiment?', British Educational Research Journal, vol. 30, no. 4, pp. 577-590.

Hargreaves, D. H. (1996) Teaching as a research based profession: possibilities and prospects, Teacher Training Agency Annual Lecture 1996 [online] Available at: http://eppi.ioe.ac.uk/ $\mathrm{cms} /$ Portals/0/PDF reviews and summaries/TTA Hargreaves lecture.pdf

Highbury College. (2013) Highbury College, Portsmouth: Outstanding Provision in Further Education, Pearson Education, Harlow, UK.

Hillier, Y. \& Morris, C. (2010) 'Critical practitioners, developing researchers: the story of practitioner research in the lifelong learning sector', Journal of Vocational Education \& Training, vol. 62 , no. 1, pp. 89-101.

Johnson, R. B. \& Onwuegbuzie, A. J. (2004) 'Mixed methods research: a research paradigm whose time has come', Educational researcher, vol. 33, no. 7, pp. 14-26.

Jones, C. \& Kennedy, G. (2011) 'Stepping beyond the paradigm wars: pluralist methods for research in learning technology', ALT-C 2011 Conference Proceedings, University of Leeds, UK, pp. 18-28, [online] Available at: http://repository.alt.ac.uk/id/eprint/2180

Keep, E. (2006) 'State control of the English education and training system - playing with the biggest train set in the world', Journal of Vocational Education \& Training, vol. 58, no. 1, pp. 47-64.

Keep, E. (2012) 'Where next for vocational education?', British Journal of Sociology of Education, vol. 33, no. 2, pp. 315-322. 


\section{Ellis et al.}

Lave, J. \& Wenger, E. (1991) Situated learning: Legitimate peripheral participation, University of Cambridge Press, Cambridge.

Linford, N. (2013) AoC in India - FE Week on Location in New Delhi, [online] Available at: http://lsect.co.uk/AoC-in-India-FE-Week-supplement.pdf

Lucas, B., et al., (2012) How to Teach Vocational Education: A Theory of Vocational Pedagogy, City and Guilds Centre for Skills Development, [online] Available at: http://www. skillsdevelopment.org/PDF/How-to-teach-vocational-education.pdf

Mitra, S. (2013) SOLE: How to Bring Self-Organized Learning Environments to Your Community, [online] Available at: http://www.ted.com/pages/sole_toolkit

Mitra, S., Dangwal, R. \& Thadani, L. (2008) 'Effects of remoteness on the quality of education: a case study from North Indian schools', Australasian Journal of Educational Technology, vol. 24, no. 2, pp. 168-180.

Office for Standards in Education, Children's Services and Skills. (2009) Virtual Learning Environments: An Evaluation of Their Development in a Sample of Educational Settings (Reference no. 070251), [online] Available at: http://www.ofsted.gov.uk/resources/virtuallearning-environments-evaluation-of-their-development-sample-of-educational-setting

Reeves, T. C., Herrington, J. \& Oliver, R. (2005) 'Design research: a socially responsible approach to instructional technology research in higher education', Journal of Computing in Higher Education, vol. 16, no. 2, pp. 96-115.

Rogers, C. (1983) Freedom to Learn for the Eighties, Charles Merrin, Columbus, OH.

Scaife, T. (2004) 'The culture of the now: barriers to research in FE', Fourth Annual Conference of the Yorkshire and Humberside Learning and Skills Research Network, Hinsley Hall, Leeds, 2 Jul 2004, [online] Available at: http://www.tlrp.org/dspace/handle/123456789/150

Stark, S. \& Torrance, H. (2005) 'Case study', in Research Methods in the Social Sciences, eds. B. Somekh \& C. Lewin, Sage, Thousand Oaks, CA, pp. 33-40.

Stenhouse, L. (1975) An Introduction to Curriculum Research and Development, Heinemann, London.

Trilling, B. \& Fadel, C. (2012) 21st Century Skills: Learning for Life in Our Times, John Wiley \& Son, San Francisco, CA.

Ufi Charitable Trust. (2012) Scaling Up: Achieving a Breakthrough in Adult Learning with Technology, The University for Industry Charitable Trust, [online] Available at: http://www. ufi.co.uk/sites/default/files/Scaling up_21_5_V3.pdf

UKCES. (2014) Working Futures 2012-2022, [online] Available at: http://www.ukces.org.uk/ publications/er83-working-futures

Vogrinc, J. \& Zuljan, M. V. (2009) 'Action research in schools-an important factor in lecturers professional development', Educational Studies, vol. 35, no. 1, pp. 53-63.

Yin, R. K. (2014). Case Study Research: Design and Methods, Sage, Thousand Oaks, CA.

Zhao, Y. (2012) World Class Learners: Educating Creative and Entrepreneurial Students. Corwin Press, Thousand Oaks, CA. 